\title{
Novel methods for determining hematopoietic stem and progenitor cell emergence in the murine yolk sac
}

\author{
CHRISTOPHER T. LUX and MERVIN C. YODER* \\ Herman B. Wells Center for Pediatric Research, Indiana University School of Medicine, Indianapolis, IN, USA.
}

\begin{abstract}
The mammalian yolk sac is known to play a prominent role in emergence of the hematopoietic system. The extent of this contribution has been a subject of debate in recent years largely due to effects of the early circulation that obscures the site of origin of hematopoietic stem and progenitor cells. This review discusses the limitations of some of the standard assays currently employed to study hematopoietic stem and progenitor cell emergence and highlights several recently reported novel methods that address this problem from new perspectives. Two methods directly alter the circulation by either preventing it from occurring in the first place or by removing vascular connections between the embryo and the yolk sac. Other approaches have altered the ability of hematopoietic cells to interact with their environment, resulting in the lack of migration or an inability to bind to potential hematopoietic niches. A third set of experiments utilize lineage tracing techniques to follow the migration of early progenitors once they enter the circulation. Taken together, these novel methods provide new evidence for the contribution of yolk sac hematopoietic stem and progenitor cells to the adult hematopoietic system.
\end{abstract}

KEY WORDS: lineage tracing, transgenic mice, embryogenesis, stromal co-culture, hemogenic endothelium

\section{Introduction}

The therapeutic administration of hematopoietic stem and progenitor cells to treat human subjects with blood disorders is based largely on the translation of studies conducted in murine models and attests to the validity of the current model of the origin, development, and function of the hematopoietic system in the mouse. Assays have been developed that allow investigators to culture and differentiate cells from the most primitive hematopoietic stem cells through a hierarchy of progenitor cell intermediates and ultimately to fully differentiated progeny. Our understanding of the embryonic development of the hematopoietic system has also been steadily advancing, but the scientific community has yet to reach full consensus on several issues regarding the temporal and spatial emergence of hematopoietic precursor cells. One of the greatest impediments to the resolution of these issues is the impact of the onset of the fetal circulation in confounding the identification of the sites of origin of the various cells. This review focuses on a variety of novel experimental models that are shedding new light on the development of hematopoietic stem and progenitor cells by addressing the confounding variable of the circulating blood cells in several innovative ways.

\section{Historical aspects of stem cell transplantation}

Early studies of hematopoietic cells revealed that when whole blood was taken from a subject, labeled, and re-infused, the labeled cells remained in the circulation for a limited period of time (Zon, 2001). This study revealed that the production of blood must be maintained throughout the life of the animal. In 1961, Till and McCulloch demonstrated that the intravenous injection of bone marrow cells into irradiated mice resulted in the formation of large hematopoietic colonies on the surface of the spleen. These colonies were determined to be the clonal product a single cell referred to as a colony forming unit-spleen (CFU-S) (Till and Mc, 1961). Cells from within the colonies could be successfully transplanted into subsequent recipients demonstrating that the CFU$S$ could not only differentiate, but could also self-renew. The realization that single cells in adult animals harbored this ability led to the theory that there lived within the marrow a population of

Abbreviations used in this paper: CFU-S, colony forming unit-spleen; HSC, hematopoietic stem cell; AGM, aorta gonad mesonephros; YS, yolk sac; KLF, Kruppel-like factor.

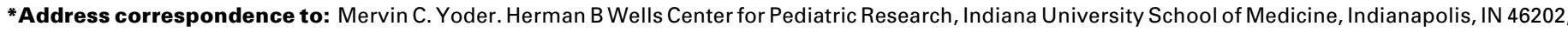
USA. Fax: +1-317-274-8679. e-mail: myoder@iupui.edu - web: www.wellscenter.iupui.edu
} 
hematopoietic stem cells that could self-renew as well as generate all lineages of hematopoietic cells of progressive degrees of maturation (Curry and Trentin, 1967).

More recent studies using cell fractionation and marrow transplantation techniques have identified a more detailed hierarchy of the hematopoietic system (Cumano et al., 1996; Cumano and Godin, 2007; Dzierzak and Speck, 2008; Ferkowicz et al., 2003; McGrath and Palis, 2005b; Medvinsky et al., 1993; Palis et al., 1999). While the bone marrow was known to contain cells capable of the long-term engraftment of an irradiated adult recipient, the CFU-S was shown to display more short-term repopulating ability (Hodgson and Bradley, 1979; Szilvassy and Cory, 1993). The long-term multilineage repopulating HSCs have been defined by two essential properties; the clonal ability to self renew and to yield the entire hematopoietic lineage tree upon transplantation into an adult recipient (Viatour et al., 2008). The earliest site of emergence of HSC that engraft adult myeloablated recipient mice is located within the embryo proper in a region called the AortaGonad-Mesonephros (AGM) at E10.5 of development. The origin of the HSCs in this site appears to reside, at least in part, in the endothelium lining the ventral wall of the aorta (Bertrand et al., 2010; Chen et al., 2009a; Dzierzak and Speck, 2008; Muller et al., 1994). The specific mechanisms that permit endothelial cells to give rise to $\mathrm{HSC}$ remains elusive, though the transcription factor Runx1 appears to be required for the transition of a endothelial cell into a hematopoietic cell (Chen et al., 2009a; Kissa and Herbomel, 2010).

The dogma that HSCs are defined by their potential to engraft and repopulate all blood lineages in a myeloablated adult recipient was challenged when cells from the developing murine yolk sac were transplanted into neonatal mice and multilineage reconstitution of the hematopoietic system into adulthood was demonstrated (Yoder et al., 1997). Not only were the neonatal mice successfully engrafted by E9.0 yolk sac and embryo proper cells, but secondary transplants using the marrow of primary engrafted mice revealed that the donor cells displayed all of the functional criteria of HSCs. These E9.0 yolk sac and embryo proper cells failed to give rise to any detectable progeny when directly infused into adult lethally ablated hosts, thus highlighting differences in the neonatal and adult hosts. In the neonatal transplant experiment, the long-term repopulating HSCs from the yolk sac and embryo proper presumably required exposure to the neonatal liver environment in order to facilitate subsequent bone marrow engraftment. Recent studies have indicated a significant change in the cycling behavior of HSC over the first two weeks of life as HSC activity becomes predominant in the bone marrow microenvironment rather than the neonatal liver (Bowie et al., 2007; Bowie et al., 2006; Dykstra et al., 2007; Sieburg et al., 2006). At present, little progress has been made in defining the specific molecular mechanisms that are involved in mediating the apparent movement of HSCs from one site to the next during murine development and the relationship between the HSCs that engraft newborn mice versus those that engraft in adult hosts remains under investigation (Dzierzak and Speck, 2008).

\section{Stromal cell co-culture}

In the late 1970's, Michael Dexter and his colleagues reported the ability to maintain hematopoietic stem cells in vitro for long periods of time by culturing them on a bone marrow stromal layer (Dexter et al., 1977). The now commonplace 'Dexter Culture' opened the door for the study of hematopoiesis ex vivo allowing multiple variables to be controlled at once. Cells could be exposed to a myriad of growth factors, culture media, and even different stromal cell lines. Thus, stromal cell and hematopoietic co-culture offers a great degree of control over experimental conditions and has led to tremendous insight into the nature of hematopoietic cell interactions with other cells within the local microenvironment. Numerous investigators have isolated and demonstrated important roles of various stromal cells (AGM, fetal liver, and bone marrow) in the process of supporting hematopoietic cell emergence from embryonic tissues (Dzierzak and Speck, 2008; Kodama et al., 1994; Matsuoka et al., 2001; Moore et al., 1997). Other investigators have developed tissue explant models that permit emergence of hematopoietic cells from the ex vivo cultured tissues, with or without the presence of other stromal cells or growth factors (Baron, 2003; Medvinsky etal., 2008; Zeigler etal., 2006).

While explant culture is superb for revealing the potential of cells from specific tissues to differentiate into various cell types, it does not necessarily equate to the natural developmental environment since the results are entirely dependent on the starting cell types and the culture environmental conditions. Nonetheless, this approach has permitted scientists to examine pre-circulation embryonic tissues for evidence of hematopoietic potential including HSCs (Cumano and Godin, 2007).

\section{Systemic blood flow obscures the site of hematopoietic cell emergence}

One of the basic impediments to the study of the in situ emergence of hematopoietic progenitors in vivo is the simple fact that they develop within the vascular lumen and are circulating as soon as the systemic circulation is functional. The first primitive erythroid progenitors develop in the blood islands of the murine yolk sac at day 7.5 of development prior to the onset of circulation (Okuda et al., 1996; Wong et al., 1986). At day 8.25 of development (4-6 somite pairs (sp)) the murine heart begins to beat and initiates the first pulses of blood flow which inexorably drives the awaiting primitive erythroblasts into the embryo proper via the vitelline circulation (Bertrand et al., 2005; Ji et al., 2003; Jones et al., 2004; McGrath et al., 2003).

The emergence of committed definitive hematopoietic progenitor cells is coincident with the first heart beat at E8.25 heralding the onset of the second wave of hematopoiesis (Palis et al., 2001). Definitive hematopoietic progenitors are detected by colony forming assay first in the yolk sac and shortly thereafter in the embryo proper (Palis et al., 1999). It has been hypothesized that these yolk sac-derived hematopoietic progenitors enter the embryo proper at the onset of circulation and seed the liver at the 28-32sp stage (Houssaint, 1981; Johnson and Moore, 1975). Regardless of their origin, once in the liver, definitive hematopoietic progenitors are stimulated to differentiate and give rise to the first definitive erythrocytes as well as myeloid cell types including mast cells, granulocytes and macrophages that leave the fetal liver and begin to circulate at E12-13 (Brotherton et al., 1979; McGrath and Palis, 2005a; Steiner and Vogel, 1973).

These events (definitive hematopoietic progenitor emergence in the YS, onset of cardiac contractions, and definitive hematopoi- 
etic progenitor detection in the embryo proper) occur in an extremely narrow window of developmental time. The circulation functionally connects the previously isolated vasculature beds of the embryo proper and the extra-embryonic yolk sac (via the vitelline vasculature) and the placenta (via the umbilical vasculature). This results in a fundamental problem when attempting to determine the origin of definitive hematopoietic progenitors during this time period as any vascular structure analyzed in vivopast 4-6sp is potentially contaminated with cells from other sites. Thus, to define the sites of origin of the hematopoietic stem and progenitor cells, one must develop approaches that circumvent the onset of blood cell redistribution via the circulation.

\section{Approaches that directly alter the onset or extent of blood circulation}

Two novel model systems have recently been utilized to address the problem of the onset of circulation confounding the study of hematopoietic cell emergence by directly altering blood flow. The first method involves the use of the VE-cadherin ${ }^{-1}$ embryo lacking proper development of vasculature structures (Rampon and Huber, 2003). Embryos lacking expression of VEcadherin exhibit defective vascular branching in extraembryonic structures by the onset of circulation (Gory-Faure et al., 1999). While the heart does beat in these embryos, the lack of interconnection between the embryo and the yolk sac via the vitelloembryonic stalk prevents the mixture of cells. The number of primitive erythrocytes present in the VE-cadherin ${ }^{-}$Y YS was not significantly different from wildtype. Furthermore, the presence of multipotent hematopoietic progenitors in the YS in the absence of contribution of cells from the embryo proper suggested that the YS was their site of origin. These results were validated by lineage specific gene expression analysis. There was no evidence of lymphoid potential through day 10.5 in this model system (Rampon and Huber, 2003).

The VE-cadherin knockout model addressed the problem of the circulation by disrupting the vascular connection of the yolk sac to the embryo proper. An alternative approach is to leave the vascular network intact, but rather block the initiation of the fetal heartbeat. NCX1 is a sodium calcium exchanger initially expressed exclusively in the fetal heart that facilitates cardiac muscle fiber contraction. When the Ncx 1 gene was disrupted by targeted gene knockout, the resultant phenotype of homozygous mutant offspring was found to be unchanged until day 8.25 at which time the heart failed to commence beating, a phenotype which is ultimately fatal (Koushik et al., 2001). As Ncx1 is not expressed in cells thought to contribute to hematopoietic development, the mutant phenotype should only effect cellular distribution via the circulation (Fig. 1). At day 9.5, Ncx $1 \%$ embryos had an intact vascular system both intra- and extra-embryonically (Lux et al., 2008)]. Staining of the mutant embryo demonstrated that the primitive erythrocytes remained in their known site of developmental origin, the yolk sac. In contrast to day 9 wild type embryos that had vessels full of primitive erythrocytes, cross sections of the

Noxit- C

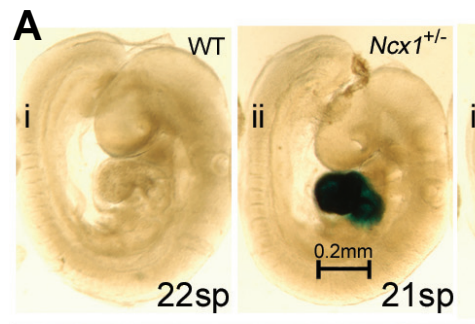

B

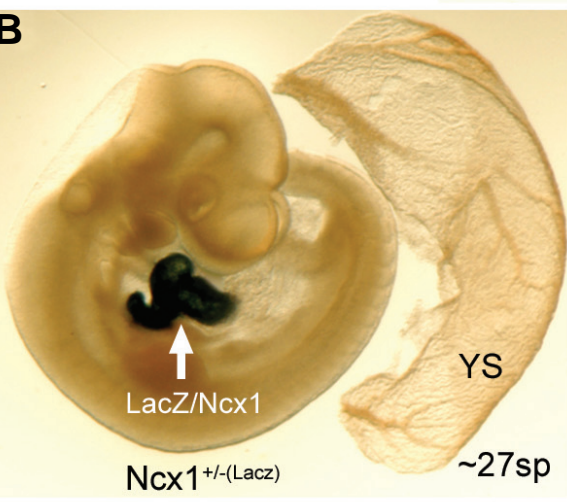

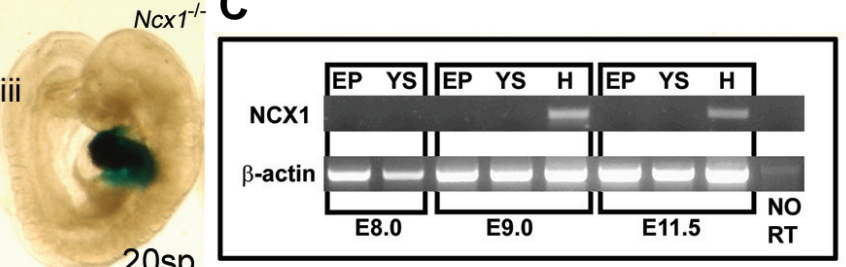

Di

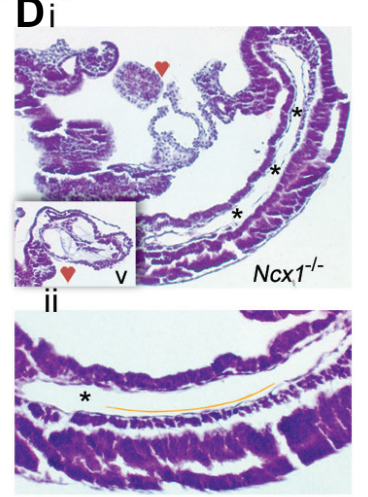

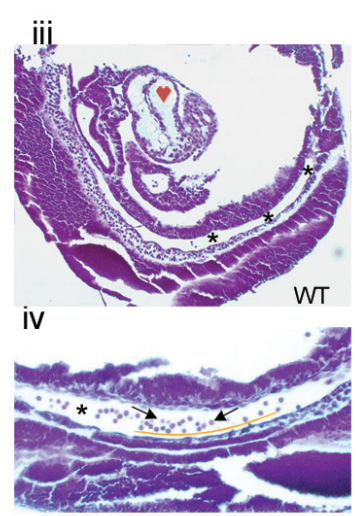

Fig. 1. The Ncx1 null mutant mouse embryo provides an in vivo circulation-free environment for study of blood cell emergence. NcX1 mutants were generated via insertion of LacZ reporter into exon 2 of the Ncx1 gene, thus all cells that normally express Ncx1 can be labeled with X-gal staining. (A) E9.5 embryos (WT(i), Ncx1+F(ii), and Ncx1-F (iii)) demonstrate that development continues well past the onset of circulation. (B) X-gal staining ( 27 $s p)$ reveals that expression of Ncx1 is restricted to the heart through E10. Importantly, there is no expression in any putative site of hematopoietic development including the $Y S$ and PSp region nor in the hematopoietic cells themselves (see blood vessels in $\mathrm{Ncx}^{+}+\mathrm{YS}$ ). (C) Ncx1 RT-PCR was conducted on embryonic tissues from various ages to confirm the $X$-gal staining. At E8.0, Ncx1 is not yet detectable in either the embryo proper or YS. At E9.0 and E11.5, Ncx1 is detected exclusively in the heart cardiomyocytes. (D) Ten-micrometer sagittal sections of hematoxylin and eosin (H\&E) stained E9.25 (19 sp) embryos. Panels Di,iii are 100x magnifications of sections that best profile the structure of the PSp region (*), which is clearly present in both WT and Ncx1\% embryos. Image Di was cut at an oblique angle compared with image Diii, leaving only a small portion of the heart and upper body in view. Image DV is an insert that transects the hypoplastic Ncx1 ${ }^{-}$heart. Images Dii,iv are 200x magnifications of the PSp (*) regions. Endothelial cells can be seen lining the vessels (below yellow line) and circulating blood cells (arrows) are seen in the WT embryo but are notably absent in the Ncx1\% embryo. The images in panelsAand B were viewed on a Leica MZ9.5 Stereomicroscope (1.0xPlanachromatic Lens/0.20 NA)(IL-3) with DFC320 CCD camera, captured with Leica application suite (LAS) software (Leica, Bannockburn, IL). Original magnification, x60. The images in panel D were viewed on a Zeiss Axioskop Stereomicroscope (Zeiss Plan-Neofluor 10x/0.30 NA (top) and 20x/0.50 NA (bottom)) with SPOT RTKE cooled color CCD camera, and imported into the SPOTAdvanced software (Diagnostic Instruments, Sterling Heights, NJ). Original magnification, x100. Reproduced without modification and with permission from Lux CJ et al. Blood, 2008: 111: 3435-3438. 
day 9.25 mutant embryo proper revealed an intact vasculature devoid of luminal blood cells (Fig. 1). Plating of cells in blood colony forming assays revealed the presence of both primitive and definitive progenitor lineages in the yolk sac of the NCX1 mutant, but interestingly, both were nearly absent in the embryo proper. The total number of hematopoietic progenitors in the conceptus was not significantly altered suggesting that cells that would typically be distributed to the embryo proper by the circulation remained in the yolk sac. Taken together, these results support a model in which both the mammalian primitive as well as the definitive hematopoietic progenitor cells originate entirely in extraembryonic tissues and it is this population of myeloerythroid progenitor cells that first seed the fetal liver.

These two model systems are not completely natural. As hematopoietic elements are thought to arise from putative hemangioblast precursors, disruption of VE-cadherin signaling could have a direct effect on these elements and affect studies of hematopoiesis (Huber et al., 2004; Ueno and Weissman, 2006). Removing the influence of blood flow is also not without consequence. It has been shown that the sheer stresses caused by the flow of blood through the developing vessels plays a critical role in blood vessel specification via signaling pathways including the induction of Kruppel-like factor (KLF)2 (SenBanerjee et al., 2004) and that hemodynamic force is necessary and sufficient to induce vessel remodeling in the yolk sac (Lucitti et al., 2007). This effect could be clearly observed in the $\mathrm{Nc} \mathrm{1}^{-/}$yolk sac where primitive erythrocytes were clearly visible pooled in large cavernous endothelial lined spaces (the un-remodeled capillary plexus) within the mutant yolk sac. Interestingly, the lack of remodeling appeared to have no effect on the production of primitive and definitive hematopoietic progenitors in the yolk sac, though it did further influence the detection of definitive progenitor cells within the embryo proper (Adamo et al., 2009). Whether these changes in vessel remodeling influence HSC development has not been directly tested in this model system, though diminishing blood flow in the zebrafish clearly impacts on production of HSC (North et al., 2009).

\section{Altering the interaction of circulating blood cells with their environment}

Once hematopoietic progenitor cells have entered the circulation, they must home to specific environments within the embryo. Novel models have been characterized in an effort to explore how these cells interact with and are impacted by their environment. One such model involves a triple transgenic knockout of RAC1 in hematopoietic stem and progenitor cells (Ghiaur et al., 2006). RAC1 is a member of the Rho GTPase family and is well known to mediate hematopoietic stem and progenitor interaction with
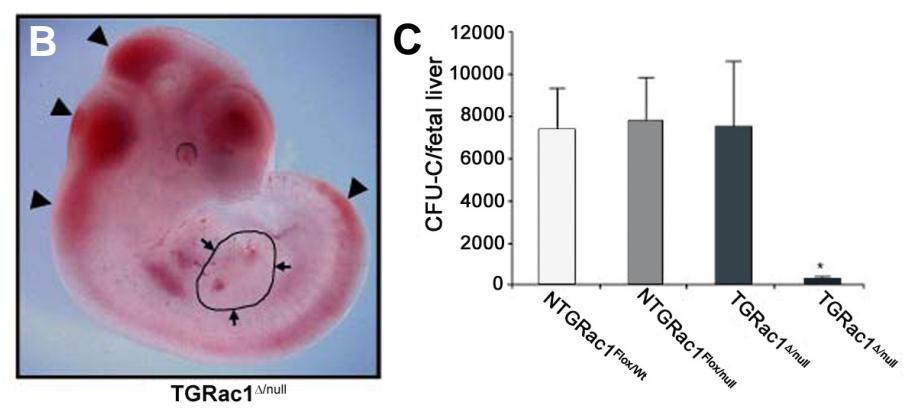

yos at E11.5. (A,B) Gross appearance of surviving TGRac1Flox/null" embryos and littermate controls at E11.5. The limbs from the right side of the embryos were removed for clarity of presentation. The appearance of the littermate controls was similar for NTGRac 1 Flox , and TGRact Floxt (hereafter referred to as "control"). The anatomic region of the fetalliver the spinal cord, a phenotype previously noted in mutant animals deficient in hematopoietic colliver flage. (C) Quantitative analysis of fetal liver hematopoiesis as analyzed by of forming units/fetal liver of F2 embryos at E11.5. Data represent mean ( $\pm S D$ ) of at least 3 embryos analyzed for each genotype. ${ }^{*} P<.01$, TGRac 1 Flox/null versus all other genotypes. Reproduced without modificaBlood, 2008: 111: 3313-3321.

hematopoietic microenvironments including those in the bone marrow (Cancelas et al., 2005). Ghiaur, et al., utilized a triple transgenic model system (Vav1Cre, Rac $1^{\text {null, }}$, and Rac flox) to $^{\text {flo }}$ delete Rac1 in hematopoietic stem and progenitor cells. While the lack of Rac1expression results in embryonic lethality attributed to a failed initiation of fetal liver hematopoiesis, this does not occur until after day 11.5 (Fig. 2). At day 10.5, all embryonic structures in Rac 1null embryos demonstrated a decreased number of colony forming units. The only tissue in which progenitor potential was not diminished was the extra-embryonic yolk sac. An analysis of the cellular migration of definitive HPCs suggested a mechanism for these findings; in the absence of RAC1 signaling, hematopoietic progenitors are unable to migrate to and seed embryonic hematopoietic niches.

The $\alpha$ integrin GPIlb, a marker of hematopoietic progenitors, is the focus of another set of experiments that are helping define cellular interactions of hematopoietic progenitors with their environment (Emambokus and Frampton, 2003). Like the RAC1 studies, the effect of knocking out GPIIb on hematopoiesis yielded interesting results. The authors demonstrated that in the absence of GPIlb, the integrin receptors for fibronectin, VLA-4 and VLA-5, display a decreased ability to bind their target ligand. Rather than an inhibition of migration, as seen with the RAC1 studies, altering the location of progenitors, the lack of GPIlb decreased the ability of progenitors to bind fibronectin in hematopoietic niches. The result was an increase in the number of progenitors in the yolk sac, fetal liver and bone marrow. Thus, GPIlb appeared to play a role in the inhibition of progenitor proliferation possibly through contact inhibition within the niche. The authors also used a Cre-loxP model to track the fates of GPIIb expressing early hematopoietic progenitors into adulthood. While their marking system successfully labeled the majority of fetal liver hematopoietic progenitors, the marked blood cell population was diminished by birth and nearly absent in the adult bone marrow compartment suggesting that GPIlb expression fails to mark the developmental precursor for adult hematopoiesis.

The genetic modifications made in each of these examples 
were generated based on current knowledge of the role these molecules play in intracellular signaling and extracellular interactions. Interaction of these gene products with yet undiscovered molecules and pathways could lead to new interpretations of the data. Rescue experiments where a wild type phenotype is achieved by replacing the disrupted molecule would help support the causal link of the knockout with the resultant phenotype. Both models also lacked control over when and where the gene was inactivated leaving room for improvement with inducible inactivation models.

\section{Tracking cells prior to the onset of circulation and seeing where they go}

Hematopoietic progenitors do not arise in a static environment, but rather move dynamically through the complex anatomy of the developing circulatory system. Tracking where these cells begin and end their journeys is no simple task. One model for tracking progenitors involves the insertion of an inducible Cre recombinase in the locus of a gene thought to be specific to hematopoietic cells (in this case RUNX1/AML1) and crossing this mouse with a loxP reporter strain (Samokhvalov et al., 2007). Only cells expressing RUNX1 at the time of exposure to tamoxifen were labeled giving temporal control over the labeling of cells. Labeling the cells at a time when RUNX1 expression is restricted to the yolk sac demonstrated that cells originating in this extraembryonic structure contribute to not only primitive and definitive hematopoietic lineages, but also to fetal lymphoid progenitors and adult hematopoietic stem cells. Furthermore, labeled cells from the day 7.5 yolk sac blood islands appeared in the endothelial lining of the umbilical vein and artery and the day 10.5 dorsal aorta, and eventually the embryonic liver suggesting at least partial colonization of these sites by cells originating from the yolk sac. Another study utilizing a model system directly labeling all RUNX1/AML1 expressing cells with a LacZ reporter was used to demonstrate the emergence of presumptive hematopoietic stem cells in the large chorioallentoic vessels as well as in the placental mesenchyme. An analysis of the placenta of the $\mathrm{Nc} \times \mathrm{T}^{-}$embryo mentioned previously demonstrated that while the number of CD41 + hematopoietic cells detected in the placenta was markedly diminished, explant culture of these cells resulted in the detection of both myeloid and lymphoid potential supporting the theory that the placenta may serve as a niche for HSCs and is possibly a site of HSC generation (Rhodes et al., 2008).

While these tracking models certainly add important new insights into the emergence of hematopoietic progenitors, there are important limitations that must be considered when drawing conclusions from their results. Embryos with heterozygous expression of RUNX1 are well known to have significant temporal alterations in the emergence of hematopoietic progenitors (Cai et al., 2000). Additionally, the tamoxifen inducible model relies heavily on the accurate staging of embryos at the time of injection and on the half-life of the drug to ensure that the correct cells are labeled. Further refinements of these models have recently been reported. Conditional deletion of RUNX1 has recently shed new light on the molecular mechanisms related to the transition of hemogenic endothelium to HSCs (Chen et al., 2009b). Furthermore, lineage tracing studies of an inducible VE-cadherin Cre line have also yielded support for an endothelial origin of HSCs (Zovein et al., 2008).

\section{Summary}

The study of the emergence of hematopoietic stem and progenitor cells has long been complicated by the fact that these cells develop in the dynamic environment of the circulatory system. Here, several novel investigative approaches have been discussed that provide new perspectives from which to view this long debated issue. We first looked at approaches that directly alter the onset or extent of the circulation in order to exclude the effects of the circulation on yolk sac hematopoietic progenitors. Other studies addressed the problem of the circulation by modifying the extent to which circulating blood cells interact with their environment, again demonstrating the emergence of blood elements in the yolk sac. A third viewpoint was provided by a series of experiments that mark pre-circulation cells and allow them to be tracked later in development. These studies have each added an important perspective to the study of early blood development allowing for the further refinement of our models of developmental hematopoiesis. Much work is still needed to continue the advancement of this field as many questions remain to be fully answered. Novel methods of investigation like those presented here will continue to play a pivotal role in efforts to unravel this complex system.

\section{References}

ADAMO, L., NAVEIRAS, O., WENZEL, P.L., MCKINNEY-FREEMAN, S., MACK, P.J., GRACIA-SANCHO, J., SUCHY-DICEY, A., YOSHIMOTO, M., LENSCH, M.W., YODER, M.C. et al. (2009). Biomechanical forces promote embryonic haematopoiesis. Nature 459: 1131-1135.

BARON, M.H. (2003). Embryonic origins of mammalian hematopoiesis. Exp Hematol 31: 1160-1169.

BERTRAND, J.Y., CHI, N.C., SANTOSO, B., TENG, S., STAINIER, D.Y. and TRAVER, D. (2010). Haematopoietic stem cells derive directly from aortic endothelium during development. Nature 464: 108-111.

BERTRAND, J.Y., GIROUX, S., GOLUB, R., KLAINE, M., JALIL, A., BOUCONTET, L., GODIN, I. and CUMANO, A. (2005). Characterization of purified intraembryonic hematopoietic stem cells as a tool to define their site of origin. Proc Nat/ Acad SCi USA 102: 134-139.

BOWIE, M.B., KENT, D.G., DYKSTRA, B., MCKNIGHT, K.D., MCCAFFREY, L., HOODLESS, P.A. and EAVES, C.J. (2007). Identification of a new intrinsically timed developmental checkpoint that reprograms key hematopoietic stem cell properties. Proc Natl Acad Sci USA 104: 5878-5882.

BOWIE, M.B., MCKNIGHT, K.D., KENT, D.G., MCCAFFREY, L., HOODLESS, P.A and EAVES, C.J. (2006). Hematopoietic stem cells proliferate until after birth and show a reversible phase-specific engraftment defect. J Clin Invest 116: 2808-2816.

BROTHERTON, T.W., CHUI, D.H., GAULDIE, J. and PATTERSON, M. (1979). Hemoglobin ontogeny during normal mouse fetal development. Proc Nat/ Acad SCi USA 76: 2853-2857.

CAI, Z., DE BRUIJN, M., MA, X., DORTLAND, B., LUTEIJN, T., DOWNING, R.J. and DZIERZAK, E. (2000). Haploinsufficiency of AML1 affects the temporal and spatial generation of hematopoietic stem cells in the mouse embryo. Immunity 13: 423-431.

CANCELAS, J.A., LEE, A.W., PRABHAKAR, R., STRINGER, K.F., ZHENG, Y. and WILLIAMS, D.A. (2005). Rac GTPases differentially integrate signals regulating hematopoietic stem cell localization. Nat Med11: 886-891.

CHEN, M.J., YOKOMIZO, T., ZEIGLER, B.M., DZIERZAK, E. and SPECK, N.A (2009). Runx1 is required for the endothelial to haematopoietic cell transition but not thereafter. Nature 457: 887-891

CUMANO, A., DIETERLEN-LIEVRE, F. and GODIN, I. (1996). Lymphoid potential, probed before circulation in mouse, is restricted to caudal intraembryonic splanchnopleura. Cel/86: 907-916. 
CUMANO, A. and GODIN, I. (2007). Ontogeny of the hematopoietic system. Annu Rev Immuno/25: 745-785.

CURRY, J.L. and TRENTIN, J.J. (1967). Hemopoietic spleen colony studies. I. Growth and differentiation. Dev Bio/15: 395-413.

DEXTER, T.M., ALLEN, T.D. and LAJTHA, L.G. (1977). Conditions controlling the proliferation of haemopoietic stem cells in vitro. J Cell Physio/91: 335-344.

DYKSTRA, B., KENT, D., BOWIE, M., MCCAFFREY, L., HAMILTON, M., LYONS, K., LEE, S.J., BRINKMAN, R. and EAVES, C. (2007). Long-term propagation of distinct hematopoietic differentiation programs in vivo. Cell Stem Cel/1: 218229.

DZIERZAK, E. and SPECK, N.A. (2008). Of lineage and legacy: the development of mammalian hematopoietic stem cells. Nat Immuno/9: 129-36.

EMAMBOKUS, N.R. and FRAMPTON, J. (2003). The glycoprotein Ilb molecule is expressed on early murine hematopoietic progenitors and regulates their numbers in sites of hematopoiesis. Immunity 19: 33-45.

FERKOWICZ, M.J., STARR, M., XIE, X., LI, W., JOHNSON, S.A., SHELLEY, W.C., MORRISON, P.R. and YODER, M.C. (2003). CD41 expression defines the onset of primitive and definitive hematopoiesis in the murine embryo. Development 130: 4393-4403.

GHIAUR, G., LEE, A., BAILEY, J., CANCELAS, J.A., ZHENG, Y. and WILLIAMS, D.A. (2006). Inhibition of RhoA GTPase activity enhances hematopoietic stem and progenitor cell proliferation and engraftment. Blood 108: 2087-2094.

GORY-FAURE, S., PRANDINI, M.H., POINTU, H., ROULLOT, V., PIGNOTPAINTRAND, I., VERNET, M. and HUBER, P. (1999). Role of vascular endothelial-cadherin in vascular morphogenesis. Development 126: 2093-2102.

HODGSON, G.S. and BRADLEY, T.R. (1979). Properties of haematopoietic stem cells surviving 5 -fluorouracil treatment: evidence for a pre-CFU-S cell? Nature 281: 381-382.

HOUSSAINT, E. (1981). Differentiation of the mouse hepatic primordium. II. Extrinsic origin of the haemopoietic cell line. Cell Differ 10: 243-252.

HUBER, T.L., KOUSKOFF, V., FEHLING, H.J., PALIS, J. and KELLER, G. (2004). Haemangioblast commitment is initiated in the primitive streak of the mouse embryo. Nature 432: 625-630.

JI, R.P., PHOON, C.K., ARISTIZABAL, O., MCGRATH, K.E., PALIS, J. and TURNBULL, D.H. (2003). Onset of cardiac function during early mouse embryogenesis coincides with entry of primitive erythroblasts into the embryo proper. Circ Res 92: 133-135.

JOHNSON, G.R. and MOORE, M.A. (1975). Role of stem cell migration in initiation of mouse foetal liver haemopoiesis. Nature 258: 726-728.

JONES, E.A., BARON, M.H., FRASER, S.E. and DICKINSON, M.E. (2004). Measuring hemodynamic changes during mammalian development. $A m \mathrm{~J}$ Physiol Heart Circ Physio/287: H1561-H1569.

KISSA, K. and HERBOMEL, P. (2010). Blood stem cells emerge from aortic endothelium by a novel type of cell transition. Nature 464: 112-115.

KODAMA, H., NOSE, M., NIIDA, S. and NISHIKAWA, S. (1994). Involvement of the c-kit receptor in the adhesion of hematopoietic stem cells to stromal cells. Exp Hemato/22: 979-984.

KOUSHIK, S.V., WANG, J., ROGERS, R., MOSKOPHIDIS, D., LAMBERT, N.A., CREAZZO, T.L. and CONWAY, S.J. (2001). Targeted inactivation of the sodium-calcium exchanger (Ncx1) results in the lack of a heartbeat and abnormal myofibrillar organization. Faseb J15: 1209-1211.

LUCITTI, J.L., JONES, E.A., HUANG, C., CHEN, J., FRASER, S.E. and DICKINSON, M.E. (2007). Vascular remodeling of the mouse yolk sac requires hemodynamic force. Development 134: 3317-3326.

LUX, C.T., YOSHIMOTO, M., MCGRATH, K., CONWAY, S.J., PALIS, J. and YODER, M.C. (2008). All primitive and definitive hematopoietic progenitor cells emerging before $\mathrm{E} 10$ in the mouse embryo are products of the yolk sac. Blood 111: 3435-3438.

MATSUOKA, S., TSUJI, K., HISAKAWA, H., XU, M., EBIHARA, Y., ISHII, T., SUGIYAMA, D., MANABE, A., TANAKA, R., IKEDA, Y. etal. (2001). Generation of definitive hematopoietic stem cells from murine early yolk sac and paraaortic splanchnopleures by aorta-gonad-mesonephros region-derived stromal cells. Blood 98: 6-12

MCGRATH and PALIS. (2005a). Hematopoiesis in the yolk sac: more than meets the eye. Exp Hemato/ 33: 1021-1028.
MCGRATH, K.E., KONISKI, A.D., MALIK, J. and PALIS, J. (2003). Circulation is established in a stepwise pattern in the mammalian embryo. Blood101: 16691676.

MCGRATH, K.E. and PALIS, J. (2005). Hematopoiesis in the yolk sac: more than meets the eye. Exp Hemato/33: 1021-1028.

MEDVINSKY, A., TAOUDI, S., MENDES, S. and DZIERZAK, E. (2008). Analysis and manipulation of hematopoietic progenitor and stem cells from murine embryonic tissues. Curr Protoc Stem Cell Bio/Chapter 2: Unit 2A 6.

MEDVINSKY, A.L., SAMOYLINA, N.L., MULLER, A.M. and DZIERZAK, E.A. (1993). An early pre-liver intraembryonic source of CFU-S in the developing mouse. Nature 364: 64-67.

MOORE, K.A., EMA, H. and LEMISCHKA, I.R. (1997). In vitro maintenance of highly purified, transplantable hematopoietic stem cells. Blood89: 4337-4347.

MULLER, A.M., MEDVINSKY, A., STROUBOULIS, J., GROSVELD, F. and DZIERZAK, E. (1994). Development of hematopoietic stem cell activity in the mouse embryo. Immunity 1: 291-301.

NORTH, T.E., GOESSLING, W., PEETERS, M., LI, P., CEOL, C., LORD, A.M., WEBER, G.J., HARRIS, J., CUTTING, C.C., HUANG, P. et al. (2009). Hematopoietic stem cell development is dependent on blood flow. Cel/137: 736-748.

OKUDA, T., VAN DEURSEN, J., HIEBERT, S.W., GROSVELD, G. and DOWNING J.R. (1996). AML1, the target of multiple chromosomal translocations in human leukemia, is essential for normal fetal liver hematopoiesis. Cel/84: 321-330.

PALIS, J., CHAN, R.J., KONISKI, A., PATEL, R., STARR, M. and YODER, M.C (2001). Spatial and temporal emergence of high proliferative potential hematopoietic precursors during murine embryogenesis. Proc Nat/ Acad Sci USA 98 4528-4533.

PALIS, J., ROBERTSON, S., KENNEDY, M., WALL, C. and KELLER, G. (1999). Development of erythroid and myeloid progenitors in the yolk sac and embryo proper of the mouse. Development 126: 5073-5084.

RAMPON, C. and HUBER, P. (2003). Multilineage hematopoietic progenitor activity generated autonomously in the mouse yolk sac: analysis using angiogenesisdefective embryos. Int J Dev Bio/47: 273-280.

RHODES, K.E., GEKAS, C., WANG, Y., LUX, C.T., FRANCIS, C.S., CHAN, D.N., CONWAY, S., ORKIN, S.H., YODER, M.C. and MIKKOLA, H.K. (2008). The emergence of hematopoietic stem cells is initiated in the placental vasculature in the absence of circulation. Cel/ Stem Cel/2: 252-263.

SAMOKHVALOV, I.M., SAMOKHVALOVA, N.I. and NISHIKAWA, S.I. (2007). Cell tracing shows the contribution of the yolk sac to adult haematopoiesis. Nature 446:1056-1061.

SENBANERJEE, S., LIN, Z., ATKINS, G.B., GREIF, D.M., RAO, R.M., KUMAR, A FEINBERG, M.W., CHEN, Z., SIMON, D.I., LUSCINSKAS, F.W. et al. (2004). KLF2 Is a novel transcriptional regulator of endothelial proinflammatory activation. J Exp Med 199: 1305-1315.

SIEBURG, H.B., CHO, R.H., DYKSTRA, B., UCHIDA, N., EAVES, C.J. and MULLER-SIEBURG, C.E. (2006). The hematopoietic stem compartment consists of a limited number of discrete stem cell subsets. Blood 107: 2311-2316.

STEINER, R. and VOGEL, H. (1973). On the kinetics of erythroid cell differentiation in fetal mice. I. Microspectrophotometric determination of the hemoglobin content in erythroid cells during gestation. J Cell Physio/81: 323-338.

SZILVASSY, S.J. and CORY, S. (1993). Phenotypic and functional characterization of competitive long-term repopulating hematopoietic stem cells enriched from 5-fluorouracil-treated murine marrow. Blood81: 2310-2320.

TILL, J.E. and MC, C.E. (1961). A direct measurement of the radiation sensitivity of normal mouse bone marrow cells. Radiat Res 14: 213-222.

UENO, H. and WEISSMAN, I.L. (2006). Clonal analysis of mouse development reveals a polyclonal origin for yolk sac blood islands. Dev Cel/11: 519-533.

VIATOUR, P., SOMERVAILLE, T.C., VENKATASUBRAHMANYAM, S., KOGAN, S., MCLAUGHLIN, M.E., WEISSMAN, I.L., BUTTE, A.J., PASSEGUE, E. and SAGE, J. (2008). Hematopoietic stem cell quiescence is maintained by compound contributions of the retinoblastoma gene family. Cel/ Stem Cel/3: 416428.

WONG, P.M., CHUNG, S.W., REICHELD, S.M. and CHUI, D.H. (1986). Hemoglobin switching during murine embryonic development: evidence for two populations of embryonic erythropoietic progenitor cells. Blood 67: 716-721.

YODER, M.C., HIATT, K., DUTT, P., MUKHERJEE, P., BODINE, D.M. and ORLIC, 
D. (1997). Characterization of definitive lymphohematopoietic stem cells in the day 9 murine yolk sac. Immunity 7: 335-344.

ZEIGLER, B.M., SUGIYAMA, D., CHEN, M., GUO, Y., DOWNS, K.M. and SPECK, N.A. (2006). The allantois and chorion, when isolated before circulation or chorio-allantoic fusion, have hematopoietic potential. Development 133: 41834192.
ZON, L.I. (2001). Hematopoiesis - A Developmental Approach. Oxford University Press, New York, New York.

ZOVEIN, A.C., HOFMANN, J.J., LYNCH, M., FRENCH, W.J., TURLO, K.A., YANG, Y., BECKER, M.S., ZANETTA, L., DEJANA, E., GASSON, J.C. et al. (2008). Fate tracing reveals the endothelial origin of hematopoietic stem cells. Cell Stem Cel/3: 625-636.

\section{Further Related Reading, published previously in the Int. J. Dev. Biol.}

See our recent Special Issue Placenta edited by Joan S. Hunt and Kent L. Thornburg at: http://www.ijdb.ehu.es/web/contents.php?vol=54\&issue=2-3

Tracing the hemangioblast during embryogenesis: developmental relationships between endothelial and hematopoietic cells

Thierry Jaffredo, Karine Bollerot, Daisuke Sugiyama, Rodolphe Gautier and Cécile Drevon Int. J. Dev. Biol. (2005) 49: 269-277

Of birds and mice: hematopoietic stem cell development Isabelle Godin and Ana Cumano Int. J. Dev. Biol. (2005) 49: 251-257

Embryonic development of the human hematopoietic system Manuela Tavian and Bruno Péault Int. J. Dev. Biol. (2005) 49: 243-250

Multilineage hematopoietic progenitor activity generated autonomously in the mouse yolk sac: analysis using angiogenesis-defective embryos

Christine Rampon and Philippe Huber Int. J. Dev. Biol. (2003) 47: 273-280

Pathways in blood and vessel development revealed through zebrafish genetics Philip S Crosier, Maggie L Kalev-Zylinska, Christopher J Hall, Maria Vega C Flores, Julia A Horsfield and Kathryn E Crosier Int. J. Dev. Biol. (2002) 46: 493-502

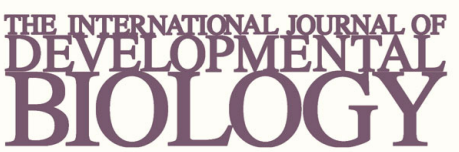

Volume 54 Nos. 6/7 Special Issue

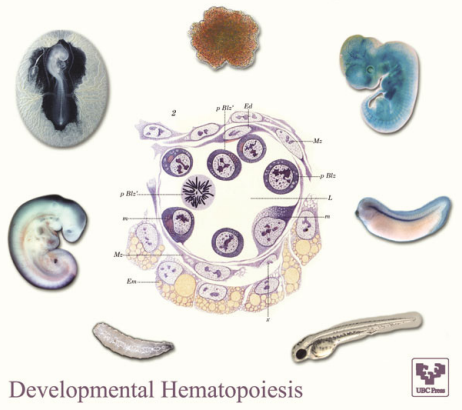

5 yr ISI Impact Factor $(2009)=3.253$

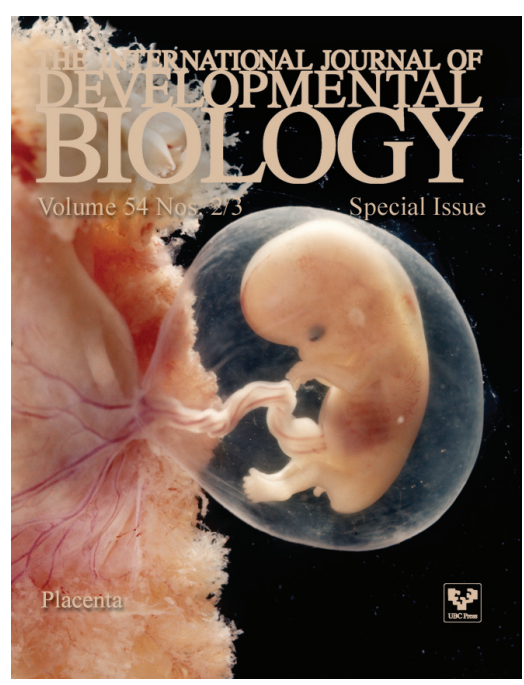

